\title{
Sympathetic innervation regulates macrophage activity in rats with polycystic ovary
}

\author{
Florencia Figueroa', Gisela Mendoza', Darío Cardozo', Fabián Mohamed², Liliana Oliveros' and Myriam Forneris' \\ ${ }^{1}$ Laboratorio de Biología de la Reproducción, Facultad de Química, Bioquímica y Farmacia, Universidad Nacional de San Luis, San Luis, Argentina \\ ${ }^{2}$ Area Morfología, Facultad de Química, Bioquímica y Farmacia, Universidad Nacional de San Luis, San Luis, Argentina
}

Correspondence should be addressed to M Forneris: mlforneris@gmail.com

\section{Abstract}

Polycystic ovarian syndrome (PCOS) is a low-grade inflammatory disease characterized by hyperandrogenism and ovarian hyperinnervation. The aim of this work is to investigate whether in vivo bilateral superior ovarian nerve (SON) section in adult rats with estradiol valerate-induced PCOS (PCO rats) affects macrophage spleen cells $(M \Phi)$ and modifies the steroidogenic ability of their secretions. Culture media of $M \Phi$ from PCO rats and PCO rats with SON section (PCO-SON rats) were used to stimulate in vitro intact ovaries. Compared with macrophages $\mathrm{PCO}$, macrophages from $\mathrm{PCO}-\mathrm{SON}$ rats released less tumor necrosis factor- $\alpha$ and nitric oxide, expressed lower Bax and $N f k b$ mRNA and showed reduced TUNEL staining. Also, in PCO rats, the SON section decreased kisspeptin and nerve growth factor mRNA expressions, without changes in Trka receptor mRNA levels. Macrophage secretions from PCO-SON rats decreased androstenedione and stimulated progesterone release in $\mathrm{PCO}$ ovaries, compared to macrophage secretions from PCO rats. No changes were observed in ovarian estradiol response. These findings emphasize the importance of the SON in spleen $M \Phi$, since its manipulation leads to secondary modifications of immunological and neural mediators, which might influence ovarian steroidogenesis. In PCO ovaries, the reduction of androstenedione and the improvement of progesterone release induced by PCO-SON M $\Phi$ secretion, might be beneficial considering the hormonal anomalies characteristic of PCOS. We present functional evidence that modulation of the immune-endocrine function by peripheral sympathetic nervous system might have implications for understanding the pathophysiology of PCOS.

\section{Key Words}

- polycystic ovary

- macrophages

- kisspeptin

- superior ovarian nerve

- steroidogenesis

\section{Introduction}

In mammalians, reproduction is a highly complex phenomenon regulated by cross-talk between the neuroendocrine and immune systems (ThyagaRajan \& Priyank 2012, Procaccini etal. 2014). Few data are available, however, on the functional significance of the ovary peripheral innervation in the pathogenesis of reproductive endocrine disorders. In rats, most of the sympathetic fibers innervating the ovaries arise from the superior mesenteric/ celiac plexus ganglia and reach the ovary through the ovarian plexus and the superior ovarian nerve (SON) (Burden 1985, Klein \& Burden 1988). SON mainly contains noradrenergic fibers from the celiac ganglion, in addition to other neuropeptides, such as vasoactive intestinal peptide and neuropeptide Y (Dissen \& Ojeda 1999). The SON fibers, travel along the suspensory ligament and are distributed in the perifollicular theca layer, in close relation with the theca internal cells, thus participating in the regulation of ovarian steroidogenesis and follicular 
development (Aguado 2002). The sympathetic nervous system enters the spleen by periarteriolar pathways and terminates in T-cell and macrophage areas (Straub 2004). In addition to the presence of adrenergic receptors in these immunocompetent cells, histological studies have demonstrated that sympathetic nerve endings contain norepinephrine (NE), among other neuropeptides (Mignini et al. 2003). Likewise, it has been reported that the $\beta_{2}$ adrenergic receptor located on macrophages exerts an anti-inflammatory effect by inhibiting nuclear factor $\kappa \mathrm{B}(\mathrm{NF} \kappa \mathrm{B})$ activation and cytokine production induced by pro-inflammatory stimuli (Farmer \& Pugin 2000), although other reports suggest that $\beta_{2}$ adrenergic receptor may promote a pro-inflammatory response by macrophages (Tan et al. 2007). NFkB has been recognized as a redoxsensitive transcription factor involved in the induction of pro-inflammatory response (Kabe et al. 2005), as well as a mediator of genes responsible for cellular proliferation and apoptosis (Puszynski et al. 2009).

In recent years, kisspeptin (kiss) has emerged as a key regulator of the mammalian reproductive axis. This peptide hormone, acts via the G-protein-coupled receptor (GPR54) and stimulates secretions of hypothalamic gonadotropinreleasing hormone neurons to control puberty onset and subsequent fertility (Clarke \& Dhillo 2016, Wahab et al. 2016). The kiss/GPR54 system is expressed in the ovarian, endothelial and immune cells of rodents and humans and in rat celiac ganglion where they colocalize with tyrosine hydroxylase neurons (Gaytán et al. 2009, Ricu et al. 2012). Intraovarian kiss/GPR54 may be regulated by sympathetic nerve activity and, together with NE, participate in the regulation of follicular dynamics (Fernandois et al. 2017). Kiss is known to be sensitive to immune/inflammatory challenge conditions and transmits these signals into the central reproductive system. In fact, decreased expression of kiss mediates acute immune/inflammatory stressinduced suppression of gonadotropin secretion in female rats (Iwasa et al. 2008).

On the other hand, Oakley et al. (2011) suggests that the spleen may serve as an immune cell reservoir for the ovary and that splenic monocytes can be mobilized in a cyclic manner to the ovaries where they differentiate into macrophages. Macrophage-derived secretory products such as tumor necrosis factor (TNF)- $\alpha$, interleukin (IL)-1, IL-6 and nitric oxide (NO), among others, exert direct effects on endocrine ovarian cells ( $\mathrm{Wu}$ et al. 2004). These signaling molecules modulate normal reproductive function but are also involved in the pathogenesis of reproductive chronic inflammatory disorders as polycystic ovarian syndrome (PCOS) (Xiong et al. 2011). PCOS is one of the most common gynecological endocrinopathies affecting women in reproductive age. This disorder is characterized by hyperandrogenism, anovulation and infertility and involves abnormalities of lipid and glucose metabolism (Lizneva et al. 2016). Although its etiology remains unknown, a potential contribution of the peripheral sympathetic system in the initiation and/or perpetuation of PCOS has been proposed (StenerVictorin et al. 2005, Wojtkiewicz et al. 2014). In particular, rats injected with a single dose of estradiol valerate (EV) develop anovulation and acyclicity, form ovarian cysts, and an increased ovarian sympathetic outflow that is accompanied by elevated synthesis of nerve growth factor (NGF) (Lara et al. 2000). Besides its function as a trophic factor for peptidergic and sympathetic neurons, NGF can act as an immunomodulatory factor through its receptors p75NGFR and TrkA, which are expressed by lymphocytes and monocytes (Thorpe et al. 1987). In the EV PCOS model, the SON section has the potential to restore estrus cyclicity and the ovulatory capacity of the ovary, supporting the theory of sympathetic hyperactivity (Barria et al. 1993).

Our studies using an EV-PCOS rat model (PCO rats) and secretions of splenocytes in culture, which is a heterogeneous cell population that includes $\mathrm{B}$ and $\mathrm{T}$ lymphocytes, macrophages as well as other cells, have suggested a functional relationship at the peripheral level between the immune, neural and endocrine systems. The increase of splenocytes $\beta$ adrenergic receptors 7 days after the SON section was shown to be related to changes in ovarian steroidogenesis when secretions of splenocytes were used to induce the release of progesterone and estradiol from the ovary as compared to control rats (Forneris et al. 2003, 2008). However, the participation of the sympathetic system in PCOS pathogenesis through the SON and its interaction with the immune system (splenic macrophages) are yet poorly understood. Thus, in this study, we investigated whether bilateral section of the SON in EV-induced PCO rats would: (1) modify the expressions of sympathetic activation (NGF and kiss) and pro-inflammatory (TNF $\alpha$ and NO) markers in macrophages and induce apoptosis in these immune cells and (2) affect the steroidogenic ability of PCO macrophages secretions and consequently modify the ovarian steroid response. Culture media of macrophages from $\mathrm{PCO}$ rats (PCO) and $\mathrm{PCO}$ rats with bilateral section of the SON (PCO-SON) were used to stimulate in vitro PCO ovaries. 


\section{Materials and methods}

\section{Materials}

Estradiol valerate (EV), RPMI 1640 medium and fetal bovine serum (FBS) were purchased from Sigma. TRIzol reagent was obtained from Invitrogen/Life Technology. Estradiol and androstenedione were provided by New England Nuclear (Boston, MA, USA). Other reagents and chemicals were of analytical grade.

\section{Animals and treatment}

Virgin adult female Holtzman rats $(180 \pm 20 \mathrm{~g}$ body weight) showing at least two regular 4-day cycles were used. They were kept under controlled temperature and lighting conditions $\left(22-24^{\circ} \mathrm{C}, 12\right.$-h light:12-h darkness) with free access to tap water and food (Cargill, Buenos Aires, Argentina). Animals were handled according to the procedures approved in the UFAW Handbook on the Care and Management of Laboratory Animals: Vol 1. Terrestrial vertebrates, 7th ed. (T Poole ed., 1999). All animal procedures were performed following protocols previously approved by the Animal Use and Care Committee of the National University of San Luis.

Sixty-three rats were used and distributed into three groups: PCO $(n=27)$ and PCO-SON $(n=27)$ for ovarian incubation, where nine rats of each group were also used to obtain macrophages from the spleen, and the Control $(n=9)$ group, where the rats were only used to obtain spleen macrophages. To induce the PCO condition, 8-week-old rats were injected with a single i.m. dose of $2 \mathrm{mg}$ of $\mathrm{EV}$ in $0.1 \mathrm{~mL}$ of corn oil as vehicle (PCO rats) (Brawer et al. 1986). The in vivo bilateral sectioning of the SON in PCO rats was performed 7 days before killing (PCO-SON), as described previously (Forneris et al. 1999). Briefly, rats were anesthetized with a mixture of $20 \mathrm{mg} / \mathrm{kg}$ ketamine and $100 \mathrm{mg} / \mathrm{kg}$ xylacine. The ovaries were exposed through bilateral dorsal incisions, the suspensory ligament enclosing the SON was lifted with fine forceps and the nerve was cut with small scissors. Immediately, the ovaries were returned to the abdominal cavity and the incisions were sutured. Control rats received an injection of the vehicle only. PCO, PCO-SON and Control rats were killed by decapitation 60 days after application of the EV (when cystic follicles appear) or the vehicle. Control rats were killed on estrus day. Trunk blood was collected and serum was stored at $-20^{\circ} \mathrm{C}$ until androstenedione concentrations were measured.

\section{Macrophage culture}

The macrophage (M $\Phi)$ culture was performed with the spleens from PCO, PCO-SON and Control rats. The tissue was sectioned into small pieces and pressed through a sterile nylon screen (200- $\mu \mathrm{m}$ mesh) to obtain the total cell populations. Cells were collected by centrifugation (1000 rpm; $5 \mathrm{~min}$ ) and resuspended in red blood cell lysis buffer (pH 7.2). Cell viability and counts were determined by the trypan blue exclusion method at $0.4 \%$. Cell viability was about $90 \%$ in all trials. Subsequently, $3 \times 10^{6}$ viable cells/mL of medium were incubated in RPMI1640 medium supplemented with $10 \%(\mathrm{v} / \mathrm{v})$ inactivated FBS, $1 \%$ (v/v) sodium pyruvate and antibiotics $(50 \mu \mathrm{g} / \mathrm{mL}$ streptomycin and $50 \mathrm{IU} / \mathrm{mL}$ penicillin), defined as basal medium (BM). After incubation for $2 \mathrm{~h}$ at $37^{\circ} \mathrm{C}$ in $95 \%$ air$5 \% \mathrm{CO}_{2}$, non-adherent cells were removed. The adherent MФ monolayer showed $90 \%$ of purity according to the morphologic analysis performed by Giemsa staining and nonspecific esterase staining (Figueroa et al. 2015). МФ from PCO rats (PCO M $)$ ), from PCO rats with bilateral SON section (PCO-SON M $\Phi$ ) and from Control rats (Control M $\Phi$ ) were plated at a density of $1 \times 10^{6}$ cells/well, preincubated in $1 \mathrm{~mL}$ of $\mathrm{BM}$ for $24 \mathrm{~h}$ and subsequently cultured for $24 \mathrm{~h}$. The respective culture media (also called M $\Phi$ secretions) were collected and used to stimulate ovaries from PCO (PCO ovaries) and PCO-SON rats (PCO-SON ovaries).

\section{Ovary incubation}

After sacrificing the rats, the PCO and PCO-SON ovaries were rapidly halved and preincubated in $1 \mathrm{ml}$ of $\mathrm{BM}$ at $37^{\circ} \mathrm{C}$ in $95 \%$ air-5\% $\mathrm{CO}_{2}$. After $15 \mathrm{~min}$, the incubation media were discarded and either $1 \mathrm{~mL}$ of $\mathrm{BM}$ or $1 \mathrm{~mL}$ of $\mathrm{M} \Phi$

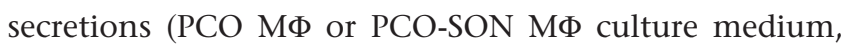
respectively) was added. Incubation was continued for $3 \mathrm{~h}$, the medium was removed and stored at $-20^{\circ} \mathrm{C}$ until measuring hormone release contents.

\section{Steroid assays}

Androstenedione (A2) levels in serum, as estradiol (E2), A2 and progesterone (P4) released in the media from ovarian incubations, were determined by radioimmunoassay using specific antisera (Forneris \& Aguado 2002). The assay sensitivity was less than $0.02 \mathrm{ng} / \mathrm{mL}$ for $\mathrm{A} 2$, $12 \mathrm{fmol} /$ tube for E2 and $5 \mathrm{ng} / \mathrm{mL}$ for P4. In all cases, the intra- and inter-assay coefficient of variation was lower than $10 \%$. The results were expressed as nanograms of P4 
and A2 per milligram of ovarian tissue (ng P4/mg tissue and ng A2/mg tissue, respectively), and as picograms of E2 per milligram of ovarian tissue (pg E2/mg tissue).

\section{Nitrite assay}

MФ culture supernatants from PCO, PCO-SON and Control rats were analyzed for NO by assaying nitrite, using the Griess reagent (Bryan \& Grisham 2007). The intra-assay coefficient of variation was lower than $10 \%$. Also, nitrite was measured in the macrophage spleen cells (MФ) supernatant treated with $1 \mathrm{mM} \mathrm{L-NG-Nitroarginine}$ methyl ester, a water-soluble inhibitor of NO synthase, in the culture medium for $24 \mathrm{~h}$. The results were expressed as millimoles of nitrite per milliliter $(\mathrm{mmol} / \mathrm{mL})$.

\section{Determination of TNF $\alpha$}

M $\Phi$ cells from PCO, PCO-SON and Control rats were incubated for $24 \mathrm{~h}$ and TNF $\alpha$ was quantified on cell-free culture supernatants by an ELISA kit (Chemicon International USA) according to the manufacturer's instructions. Cytokine concentration was determined by extrapolation from the TNF $\alpha$ standard curve and expressed as $\mathrm{pg} / \mathrm{mL}$.

\section{RNA extraction and semiquantitative RT-PCR}

Total RNA was extracted from M $\Phi$ culture using TRIzol reagent. The semi-quantitative analysis of mRNA was performed using a one-step RT-PCR method (Access RT-PCR system, Promega). All components for RT and PCR were assembled in $50 \mu \mathrm{L}$ reactions containing $5 \times$ reaction buffer (10 mM Tris-HCl, pH 8.3, $50 \mathrm{mM} \mathrm{KCl}), 3 \mathrm{mM} \mathrm{MgCl}_{2}$, $10 \mathrm{mM}$ dNTP mixture, $1 \mu \mathrm{M}$ of each gene-specific primers, $2 \mu \mathrm{g}$ template RNA, 5 units of AMV reverse transcriptase and 5 units of Tfl DNA polymerase. The amplification of cDNA was performed under the following conditions: denaturation at $94^{\circ} \mathrm{C}$ for $2 \mathrm{~min}$ followed by 35 cycles of denaturation at $94^{\circ} \mathrm{C}$ for $30 \mathrm{~s}$, annealing for $1 \mathrm{~min}$ and extension at $72^{\circ} \mathrm{C}$ for $2 \mathrm{~min}$. The reaction was completed with a final extension at $72^{\circ} \mathrm{C}$ for $7 \mathrm{~min}$ (thermal cycler). The primer sequences are presented in Table 1 . The PCR products were resolved on $2 \%$ agarose gel electrophoresis containing $0.5 \mathrm{mg} / \mathrm{mL}$ GelRed. Band intensities of RT-PCR products were quantified using NIH Image software. The relative abundance of each band was normalized according to the housekeeping Gapdh gene. Thus, results were expressed as mRNA/Gapdh in arbitrary units.

\section{Identification of apoptotic nuclei}

The in situ localization of nuclei exhibiting apoptotic DNA fragmentation from PCO, PCO-SON and Control rats were kept in M $\Phi$ cultured for $24 \mathrm{~h}$. The DeadEnd Colorimetric TUNEL System kit (Promega) was used according to the manufacturer's instructions. Briefly, at the end of the cell culture period, the overlying medium was removed and $1 \times 10^{6}$ macrophages were harvested after $0.2 \%$ trypsin (Sigma) treatment. The cells were washed with ice-cold PBS, centrifuged and mounted on silane-coated slides to develop the TUNEL technique. Under light microscopy, the number of TUNEL-positive cells per high-power field $(\times 100)$ was counted. Cells showing dark brown staining from the colorimetric reaction were considered positive

Table 1 Primer sequences for RT-PCR.

\begin{tabular}{|c|c|c|c|}
\hline Gene & Primer $\left(5^{\prime}-3^{\prime}\right)$ & Product (bp) & Annealing temp $\left({ }^{\circ} \mathrm{C}\right)$ \\
\hline \multirow[t]{2}{*}{ Tnfa } & Forward: AAGTTCCCAAATGGCCTCCСTCTCATC & 485 & 60 \\
\hline & Reverse: GAGGCTGACTTTCTCCTGGTATGAAA & & \\
\hline \multirow[t]{2}{*}{ Bax } & Forward: ACTAAAGTGCCCGAGCTGAT & 190 & 61 \\
\hline & Reverse: TTCTTCCAGATGGTGAGCGA & & \\
\hline \multirow[t]{2}{*}{$B c / 2$} & Forward: CACCCCTGGCATCTTCTCCTT & 519 & 61 \\
\hline & Reverse: AGCGTCTTCAGAGACAGCCAG & & \\
\hline \multirow[t]{2}{*}{ Trka } & Forward: TGCTGCTGCTGCTGATTCTAGG & 716 & 61 \\
\hline & Reverse: AGGAATGAGGTTGTCGGTGGTG & & \\
\hline \multirow[t]{2}{*}{ Ngf } & Forward: TGATCGGCGTACAGGCAGAAC & 582 & 65 \\
\hline & Reverse: AAGGTGTGAGTCGTGGTGCAG & & \\
\hline \multirow[t]{2}{*}{$N f k b$} & Forward: CATGAAGAGAAGACACTGACCATGGAAA & 329 & 59 \\
\hline & Reverse: TGGATAGAGGCTAAGTGT AGACACG & & \\
\hline \multirow[t]{2}{*}{ Kiss } & Forward: TGG CAC CTG TGG TGA ACC CTG AAC & 301 & 62 \\
\hline & Reverse: GCC ACC TGC CTC CTG CCG TAG CGC & & \\
\hline \multirow[t]{2}{*}{ Gapdh } & Forward: GGGCTGCCTTCTCTTGTGAC & 325 & 60 \\
\hline & Reverse: CGCCAGTAGACTCCACGACA & & \\
\hline
\end{tabular}

bp, base pairs. 
for DNA fragmentation. A total of 50 fields were analyzed in all cases, and the result was expressed as a percentage of TUNEL-positive cells.

\section{Statistical analysis}

The results are expressed as the mean \pm standard error (s.E.M.). Statistical analysis was performed using GraphPad Prism version 5.0 for Windows. Student's t-test and ANOVA (parametric test) followed by the Tukey-Kramer test were used to compare the means between two groups for multiple comparisons. A value of $P<0.05$ was considered statistically significant.

\section{Results}

\section{Effect of SON section on TNF $\alpha$ and nitrite release} from PCO macrophages

The measurement of serum A2 levels showed a decrease in PCO-SON rats compare to PCO rats, reaching a similar value to control rats (PCO: $1.88 \pm 0.10$; PCO-SON: $1.50 \pm 0.12$; C: $1.45 \pm 0.07 ; \mathrm{ng} / \mathrm{mL}$; PCO vs PCO-SON and $\mathrm{C}$ rats, $P<0.05)$. This, along with our previous results showing that the androgen microenvironment induces the production of TNFo by PCO MФ (Figueroa et al. 2015), led us to determine whether the SON section affects TNF $\alpha$ release and its mRNA expression in PCO MФ. As shown in Fig. $1 \mathrm{~A}$ and $\mathrm{B}$, both the amount of TNF $\alpha$ released and its mRNA levels decreased in PCO-SON M $\Phi$ compared with PCO M $\Phi(P<0.05$ and $P<0.01$, respectively), reaching a value near to control.

The results of nitrite released from $\mathrm{M} \Phi$ are presented in Fig. 2. In a previous study, we observed that $M \Phi$ from PCO rats released more NO than Control M $\Phi$ (Figueroa et al. 2015). In this case, the SON section caused a decrease in the release of nitrites from PCO-SON M $\Phi$ in relation to PCO M $\Phi(P<0.05)$. When Control, PCO and PCO-SON $\mathrm{M} \Phi$ were exposed to $1 \mathrm{mM}$ L-NAME in the culture medium for $24 \mathrm{~h}$, very low nitrite levels were observed $(P<0.001)$ indicating that nitrite levels released from non-exposed $\mathrm{M} \Phi$ can be associated to NO production.

\section{Influence of PCO condition and SON section on the macrophage mRNA expression of $B a x, B c / 2$ and Nfkb}

Presented in Fig. 3A and B are the results of Bax (proapoptotic) and Bcl2 (anti-apoptotic) mRNA levels
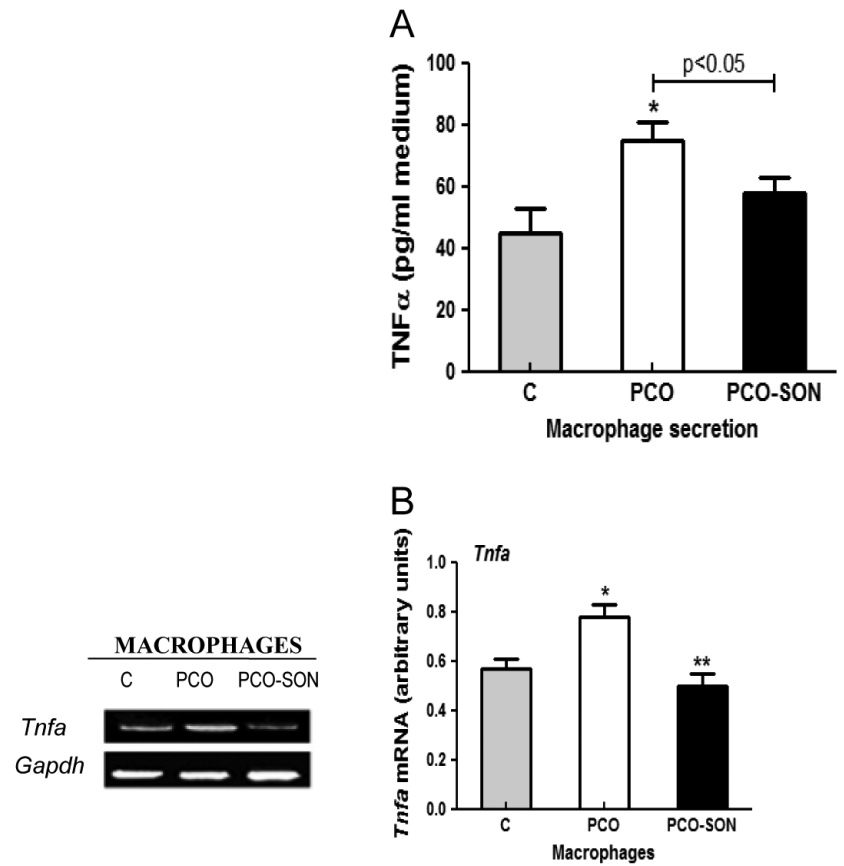

Figure 1

(A) Levels of tumor necrosis factor $\alpha$ (TNF $\alpha$ ) released from spleen macrophages $(M \Phi)$ of Control rats $(C)$, rats with polycystic ovary (PCO), and $\mathrm{PCO}$ rats with bilateral section of the superior ovarian nerve performed 7 days before killing (PCO-SON). MФ were cultured with RPMI medium for $24 \mathrm{~h}$. The graph represents the means \pm S.E.M. from three independent experiments with three rats per group. (B) Tnfa mRNA expression in MФ from C, PCO and PCO-SON rats. Target mRNA (485bp) was normalized by the level of Gapdh mRNA ( $325 \mathrm{bp}$ ). The bars represent the mean \pm S.E.M. of three independent experiments with three rats per group. ${ }^{*} P<0.05$ vs $C M \Phi$ and $* * P<0.01$ vs $P C O M \Phi$.

corrected for Gapdh expression in Control, PCO and PCO-SON M $\Phi$. An increase of the Bax mRNA expression can be observed in PCO M $\Phi(P<0.01)$ compared with Control

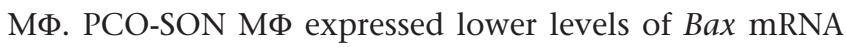
$(P<0.05)$ in relation to PCO MФ. As shown in Fig. 3B, no difference in the $B c l 2$ mRNA expression was observed between PCO M $\Phi$ and Control M $\Phi$; however, the levels of $B c l 2$ mRNA in PCO-SON M $\Phi$ were higher than those in PCO M $\Phi(P<0.05)$. Based on these results, the Bax/Bcl2 ratio decreased in PCO-SON M $\Phi$ compared to PCO M $\Phi$ $(P<0.01)$. As shown in Fig. 3C, no significant change in $N f k b$ mRNA expression was observed between Control $\mathrm{M} \Phi$ and PCO M $\Phi$, while the SON section decreased $N f k b$ expression with respect to PCO MФ $(P<0.01)$.

\section{Effect of SON section on the macrophages TUNEL staining in PCO condition}

Figure 4 shows the apoptotic nuclei identified by the colorimetric TUNEL assay in control, PCO and PCO-SON 


\begin{tabular}{l|l|l|c|}
$\begin{array}{l}\text { Journal of } \\
\text { Endocrinology }\end{array}$ & $\begin{array}{l}\text { Sympathetic innervation and } \\
\text { macrophages }\end{array}$ & $\mathbf{2 3 8 : 1}$ \\
\hline
\end{tabular}

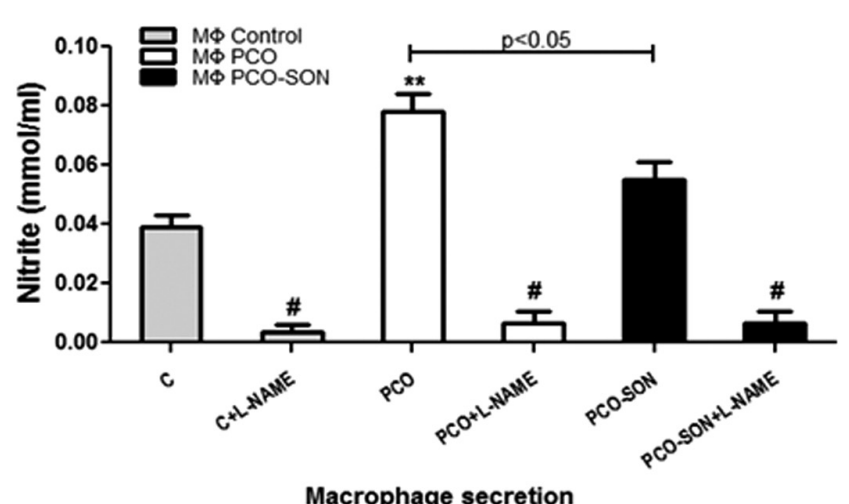

Figure 2

Levels of nitrites secreted from spleen macrophages $(M \Phi)$ of Control rats (C), rats with polycystic ovary (PCO), and PCO rats with bilateral section of the superior ovarian nerve performed 7 days before killing (PCO-SON). $M \Phi$ were cultured with RPMI medium, in presence or absence of nitric oxide synthase inhibitor (L-NAME), for $24 \mathrm{~h}$. The graph represents the means \pm S.E.M. from three experiments with three rats per group. ${ }^{*} P<0.001$ vs $M \Phi$ without L-NAME treatment and $* * P<0.01$ vs $C$ M $\Phi$.

M $\Phi$ cultured for $24 \mathrm{~h}$ in RPMI medium. The number of apoptotic cells was higher in PCO M $\Phi$ compared to Control M $\Phi(P<0.01)$, and the SON section decreased TUNEL-positive cells in PCO MФ $(P<0.05)$.

\section{Effect of SON section on Ngf, Trka and Kiss mRNA expressions in macrophages}

It is known that NGF bound to its TrkA receptor stimulates in vitro the production of TNF $\alpha$ (Barouch et al. 2001). Figure 5A shows that PCO M $\Phi$ expressed higher levels of Ngf mRNA compared with Control $\mathrm{M} \Phi(P<0.01)$, while PCO-SON M $\Phi$ showed lower neurotropin gene expression in relation to PCO and Control M $\Phi(P<0.01)$. As shown in Fig. 5B, no significant differences in Trka mRNA expression were observed between Control, PCO and PCO-SON MФ. Kiss mRNA expression has been detected in peripheral blood leukocytes but no data are available of this peptide expression in rat spleen MФ. As shown in Fig. 5C, Kiss mRNA expression was higher in PCO MФ compared to Control M $\Phi(P<0.05)$, but it showed a significant decrease

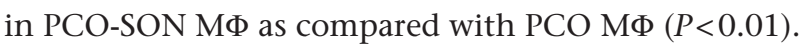

\section{Effect of secretions of $\mathrm{M \Phi}$ from PCO rats with and without SON section on the ovarian steroids release}

In order to establish whether the SON section affects the steroidogenic ability of PCO and PCO-SON M $\Phi$ secretions, the ovaries from PCO and PCO-SON rats were incubated in the presence or absence of these secretions, followed by measurement of A2, E2 and P4 release to the incubation

\begin{tabular}{|lr} 
http://joe.endocrinology-journals.org & ○ 2018 Society for Endocrinology \\
https://doi.org/10.1530/JOE-17-0736 & Published by Bioscientifica Ltd. \\
& Printed in Great Britain
\end{tabular}
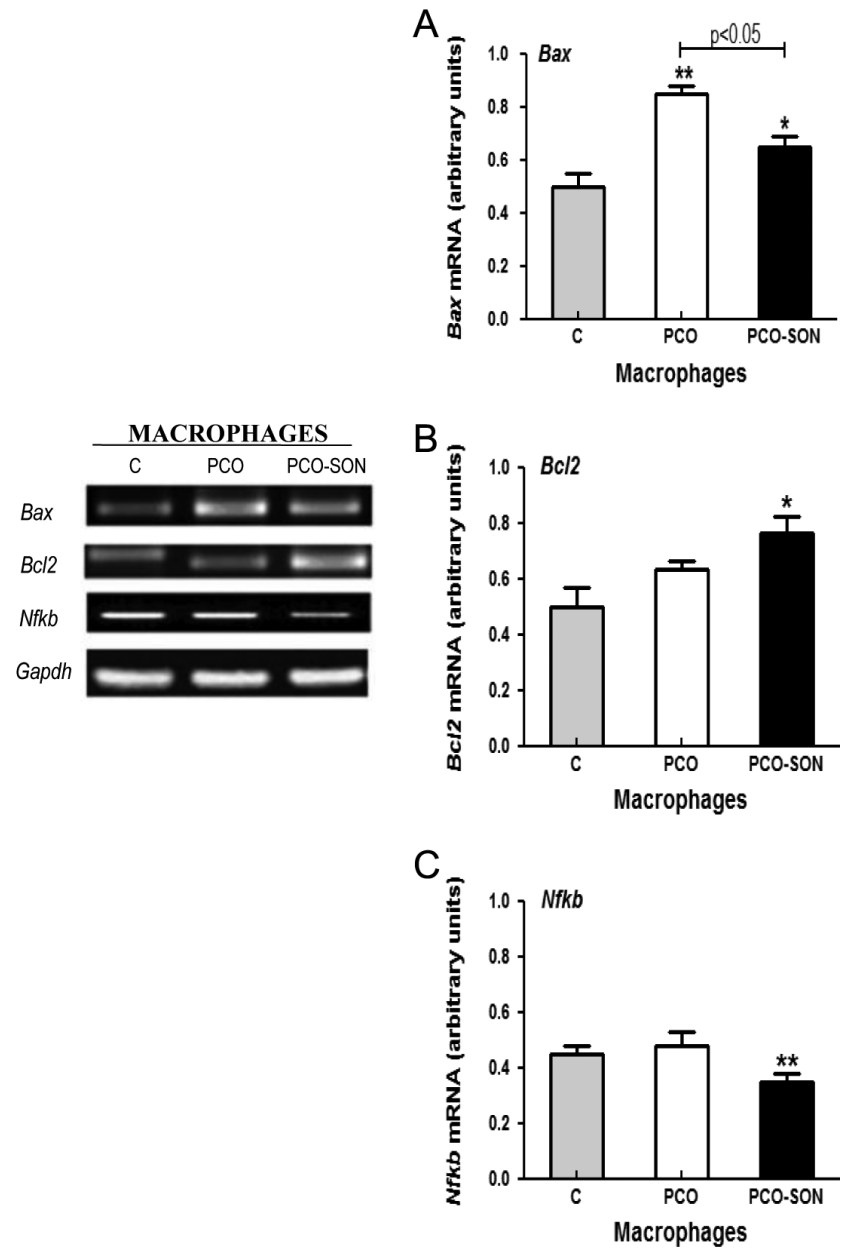

Figure 3

Expression of spleen macrophages (M $\Phi)$ genes from Control rats (C), rats with polycystic ovary (PCO) and PCO rats in which bilateral section of the superior ovarian nerve was performed 7 days before killing (PCO-SON). Representative RT-PCR analysis for (A) Bax (190bp), (B) Bc/2 (519bp) and (C) $N f k b(329 \mathrm{bp})$. Macrophages were cultured with RPMI medium for $24 \mathrm{~h}$. Target mRNA was normalized by the level of Gapdh mRNA (325 bp). Results are expressed as mean \pm S.E.M. of three independent experiments, each experiment performed with three rats per group. Bax: ${ }^{*} P<0.05$ and ${ }^{*} * P<0.01$ vs $C M \Phi ; B c / 2:{ }^{*} P<0.05$ vs $P C O M \Phi ; N f k b: * * P<0.01$ vs $P C O M \Phi$.

medium. As shown in Fig. 6A, in basal conditions, A2 release from PCO-SON ovaries was not modified in relation to PCO ovaries. The secretions of PCO M $\Phi$ and PCO-SON M $\Phi$ had a stimulatory effect on A2 release from PCO and PCO-SON ovaries, compared to their respective basal values $(P<0.001)$. In PCO ovaries, PCO-SON M $\Phi$ secretions induced a lower $\mathrm{A} 2$ release compared with PCO MФ secretions $(P<0.01)$, suggesting that the SON section modifies M $\Phi$ and, consequently, the steroidogenic ability of their secretion. The PCO-SON ovaries released less A2 with PCO-SON M $\Phi$ secretions compared to PCO ovaries $(P<0.05)$. After stimulation of PCO-SON ovaries with the PCO M $\Phi$ secretions, the A2 release was decreased 


\begin{tabular}{|l|l|l||c|c|}
\hline $\begin{array}{l}\text { Journal of } \\
\text { Endocrinology }\end{array}$ & F Figueroa et al. & $\begin{array}{l}\text { Sympathetic innervation and } \\
\text { macrophages }\end{array}$ & $\mathbf{2 3 8 : 1}$ & $\mathbf{3 9}$ \\
\hline
\end{tabular}

A
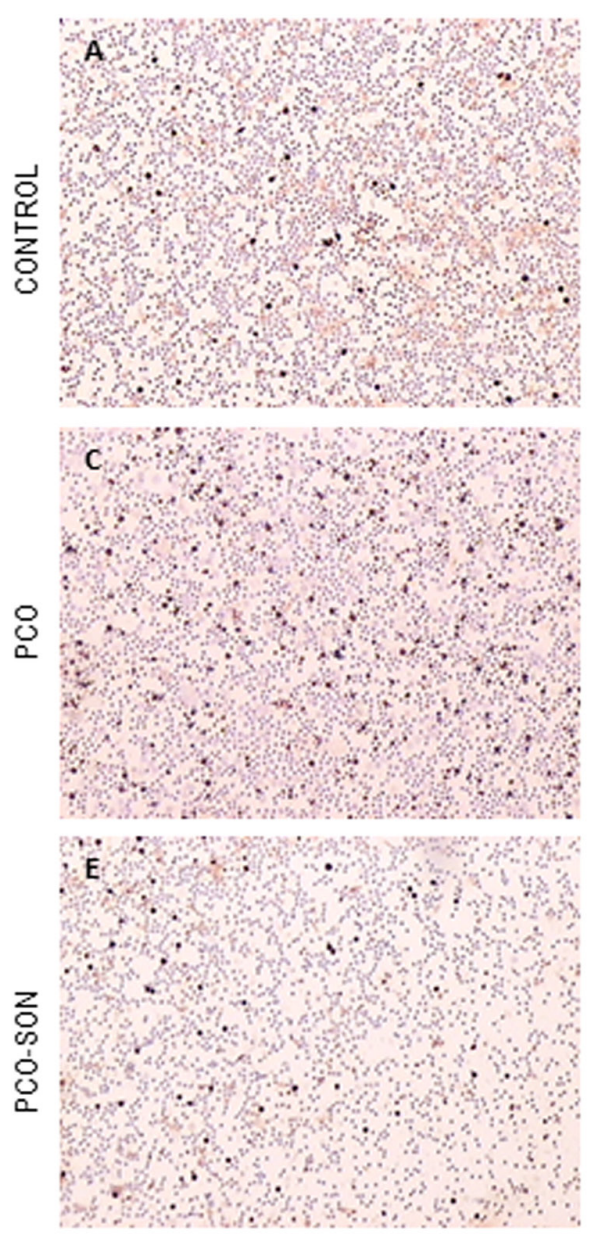

\section{MACROPHAGES}
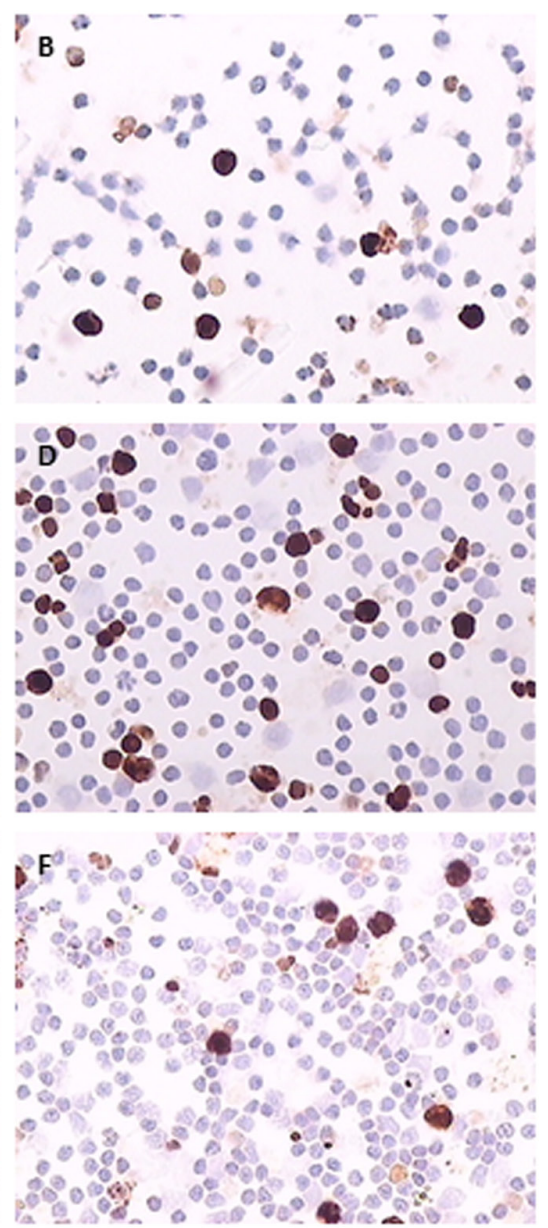

\section{B}

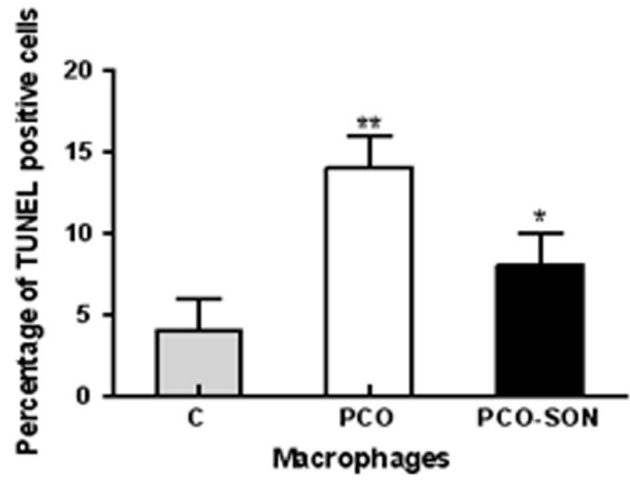

compared to PCO ovaries $(P<0.05)$. However, the decrease of A2 release from PCO-SON ovaries with PCO-SON M $\Phi$ secretions was more pronounced with respect to PCO M $\Phi$ secretions $(P<0.01)$.

Figure $6 \mathrm{~B}$ shows that, in basal conditions, similar E2 levels were released by both PCO and PCO-SON ovaries. PCO M $\Phi$ and PCO-SON M $\Phi$ secretions induced higher E2 release from PCO and PCO-SON ovaries than their respective basal values $(P<0.001$ and $P<0.05$, respectively). In PCO ovaries, PCO-SON M $\Phi$ secretions did not significantly modify E2 release compared with PCO $\mathrm{M} \Phi$ secretions. As it was observed with the release of A2, PCO-SON ovaries released lower E2 than PCO ovaries $(P<0.01)$ in presence to PCO-SON M $\Phi$ secretions. After stimulation of PCO-SON ovaries with the PCO M $\Phi$ secretions, estradiol release was similar to that of PCO ovaries.

Figure 6C shows that, in basal conditions, $\mathrm{P} 4$ release from PCO-SON ovaries did not change in relation to PCO
Figure 4 macrophages (M $\Phi)$ of Control (C), PCO and PCO-SON rats, cultured for $24 \mathrm{~h}$ in RPMI medium. (A) Representative photomicrographs of the shows a positive reaction. Magnification $A, C$ and E: 40x; B, D and F: 100x. Counter-staining: hematoxylin. (B) The bars indicate the number of apoptotic macrophage nuclei from three group; 50 fields per rat were analyzed. ${ }^{*} P<0.01$ vs $C M \Phi ; * P<0.05$ vs $P C O M \Phi$. A full colour version of this figure is available at https://doi. org/10.1530/JOE-17-0736. 


\begin{tabular}{l|l|l|c|}
$\begin{array}{l}\text { Journal of } \\
\text { Endocrinology }\end{array}$ & $\begin{array}{l}\text { Sympathetic innervation and } \\
\text { macrophages }\end{array}$ & $\mathbf{2 3 8 : 1}$ \\
\hline
\end{tabular}
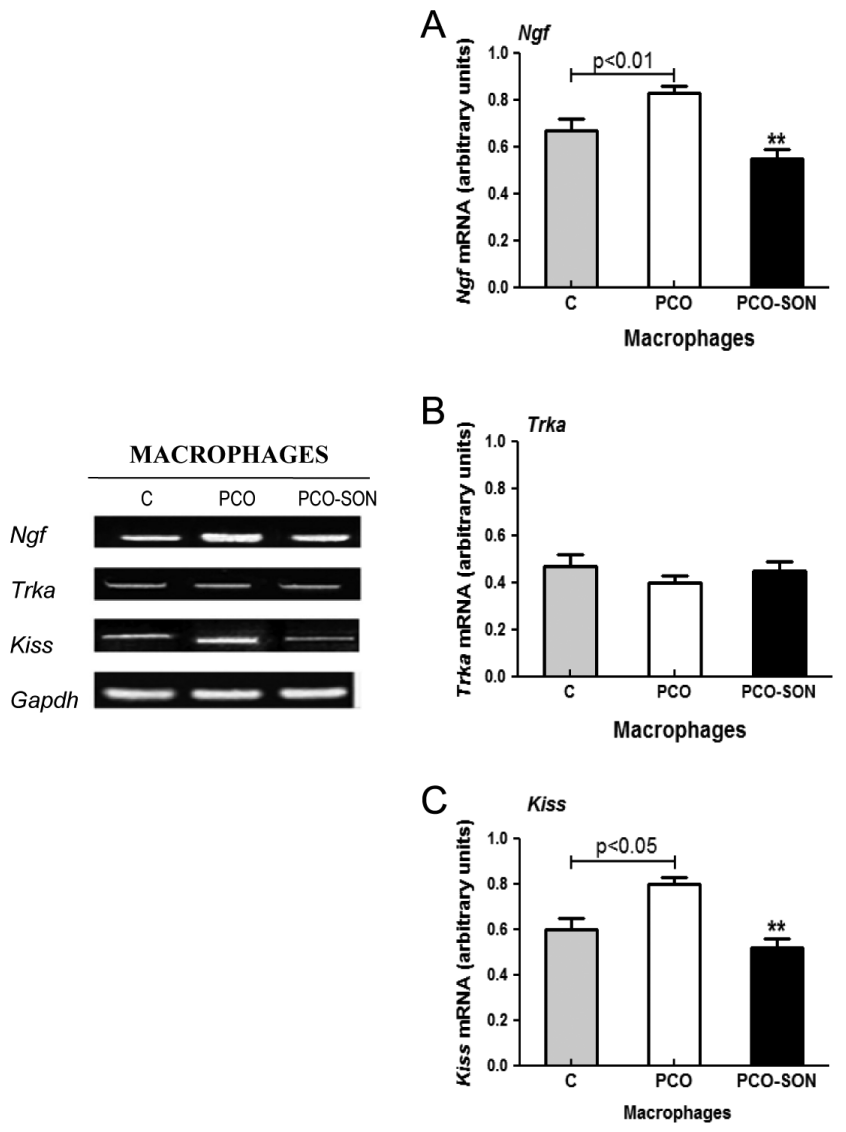

Figure 5

Spleen macrophages $(\mathrm{M} \Phi)$ mRNA expression of $(A)$ nerve growth factor (Ngf, $582 \mathrm{bp}),(B)$ Trka receptor (716 bp) and (C) kisspeptin (Kiss, $301 \mathrm{bp})$. Macrophages from Control rats (C), rats with polycystic ovary (PCO) and $\mathrm{PCO}$ rats in which bilateral section of the superior ovarian nerve was performed 7 days before killing (PCO-SON). M $\Phi$ were cultured with RPMI medium for $24 \mathrm{~h}$. Target mRNA was normalized by the level of Gapdh mRNA ( $325 \mathrm{bp}$ ). The bars represent the mean \pm S.E.M. of three independent experiments with three rats per group. ${ }^{*} P<0.01$ vs PCO M $\Phi$.

ovaries. The secretions of both PCO M $\Phi$ and PCO-SON M $\Phi$ had a stimulatory effect on P4 release from PCO and PCO-SON ovaries, compared to their respective basal values $(P<0.001)$. PCO ovaries released more P4 after stimulation with PCO-SON M $\Phi$ secretions in relation to PCO M $\Phi$ secretions $(P<0.01)$. Besides, the P4 release from PCO-SON ovary incubated with culture medium from PCO-SON M $\Phi$ was lower compared to the corresponding PCO ovary $(P<0.05)$. After stimulation of PCO-SON ovaries with the PCO M $\Phi$ secretions, the P4 release was decreased, in relation to PCO ovaries $(P<0.05)$. The secretions of PCO-SON M $\Phi$ had a greater stimulatory effect on P4 release from PCO-SON ovaries than PCO M $\Phi$ secretions $(P<0.01)$.

These data indicate that after SON section both macrophages and ovaries are compromised.

\begin{tabular}{|lr}
\hline http://joe.endocrinology-journals.org & ( 2018 Society for Endocrinology \\
https://doi.org/10.1530/JOE-17-0736 & Published by Bioscientifica Ltd. \\
& Printed in Great Britain
\end{tabular}
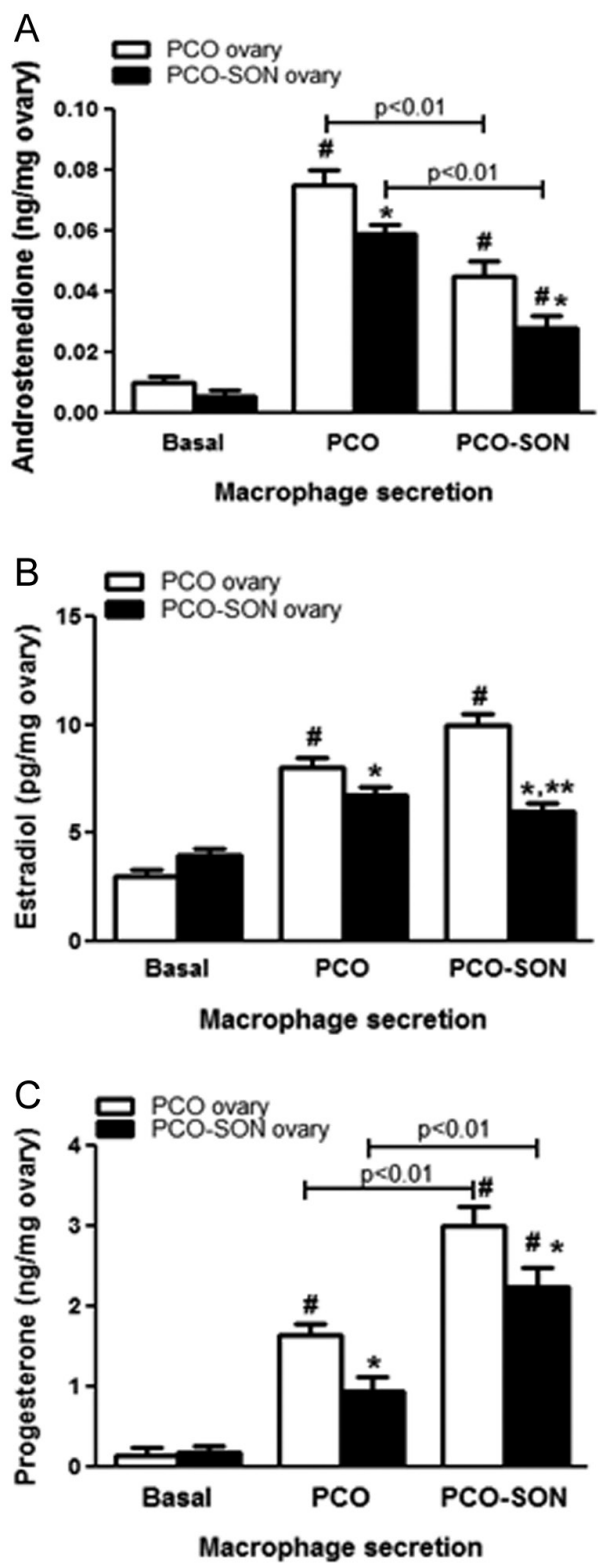

Figure 6

In vitro (A) androstenedione, $(\mathrm{B})$ estradiol and (C) progesterone release from PCO and PCO-SON ovaries. Ovaries were stimulated with either basal medium (basal) or culture medium of PCO and PCO-SON macrophages (all being macrophage secretions) for $3 \mathrm{~h}$. The graph represents the mean \pm S.E.M. of three independent experiments, each experiment performed with three PCO and three PCO-SON rats. (A) $\# P<0.001$ vs respective basal values, ${ }^{*} P<0.05$ vs respective $P C O$ ovaries; (B) ${ }^{\#} P<0.001$ and $* P<0.05$ vs respective basal value; $* * P<0.01$ vs respective PCO ovaries; (C) $\# P<0.001$ vs respective basal values; $* P<0.05$ vs respective $\mathrm{PCO}$ ovaries.

\section{Discussion}

There is growing interest in the complex relationship between the nervous, endocrine and immune systems in the regulation of reproduction and how its alteration 
can result in the development of illness. The PCOS is an endocrinopathy characterized by anovulation, infertility, hyperandrogenism and metabolic disorders in women of reproductive age. In addition to the compromise of the axis hypothalamus-hypophysis-ovary in PCOS, the contribution of the peripheral sympathetic system has been demonstrated by significant changes in the distribution pattern and density of catecholaminergic fibers in the ovary, in both human and animals (Stener-Victorin et al. 2005, Wojtkiewicz et al. 2014). The ovarian adrenergic fibers come from the SON, whose neuronal bodies are found in the celiac ganglion, where fibers that enter the spleen also originate (Bellinger et al. 1989). In the present study, we have shown in an EV-induced rat PCO model that the SON is involved in neuroimmunoendocrine regulation at peripheral level and that the bilateral section of the SON modifies the steroidogenic ability of splenic $M \Phi$ as well as expression of the neural and proinflammatory markers in these immune cells.

The nerve endings containing NE are distributed in specific compartments of the white pulp in the spleen and make direct contact with immunocompetent cells, which express adrenergic receptors (Mignini et al. 2003). Tan et al. (2007) have suggested that $\beta_{2}$ adrenergic receptor activation stimulates pro-inflammatory cytokine production in macrophages via PKA and NFkB independent mechanisms. Knowing that in vivo SON section modifies the number of splenocyte $\beta$ adrenergic receptors (Forneris et al. 1999), it can be suggested that the decrease of mRNA expression of Tnfa as well as of TNF $\alpha$ release from PCO-SON M $\Phi$ may be related to lower NE levels reaching the spleen from the celiac ganglion. The possibility is not ruled out that other neurotransmitters or neuropeptides reaching the spleen may contribute to modulation of not only the TNF $\alpha$ release but also other cytokines release in MФ. In this regard, Oliveros et al. (2001) have shown that the secretions of the cultured splenocytes from SON section rats produced a decrease of P4 and an increase of E2 release from intact ovaries. This steroidogenic response was reverted when ovaries were incubated with culture medium of SON sectioned rat splenocytes previously treated with vasoactive intestinal peptide or neuropeptide Y. This indicates that the spleen receives neuropeptides by neural route.

A potential role of the sympathetic nerve system in regulating inflammatory processes in PCOS has been proposed (Shorakae et al. 2015). Studies in cultured human in vitro fertilization-derived granulosa cells showed that $\mathrm{NE}$ and dopamine stimulate the generation of reactive oxygen species (Saller et al. 2014). In the present work, it was observed that the SON section decreases nitrite release and the mRNA expression of the inflammatory transcription factor $N f k b$ in PCO MФ. Considering our previous reports (Forneris et al. 1999, Oliveros et al. 2001, Figueroa et al. 2012) and the data presented in this study, it can be suggested that the SON modulates in vivo, through the celiac ganglion in a retrograde way, the TNF $\alpha$ and NO release from PCO МФ.

On the other hand, Liu et al. (2004) have shown that in vitro treatment of human M $\Phi$ with TNFo induces mitochondrial damage and promotes DNA fragmentation in association with inhibition of $\mathrm{NF \kappa B}$. We have shown here that the $\mathrm{Bax} / \mathrm{Bcl} 2$ ratio and the apoptotic nuclei number were increased in PCO М $\Phi$ compared with Control MФ, indicating that PCO MФs are more susceptible to apoptosis. This observation could be linked with the increase of TNF $\alpha$ and/or NO released by PCO MФ. It has been reported that $\mathrm{TNF} \alpha$ induces apoptosis in different cells types through NO production via upregulation of iNOS expression (Song et al. 2000, Sagoo et al. 2004).

Conversely, the SON section in EV-PCO rats reversed these apoptotic parameters in PCO M $\Phi$ and decreased the levels of $\mathrm{TNF} \alpha$ released and its mRNA expression, as well as $N f k b$ mRNA levels. It is known that in some circumstances, activation of NFkB appears to sensitize cells to programmed cell death (Perkins 2007). Such reduction of apoptotic markers in PCO-SON M $\Phi$ could be related to a drop in NE release in the spleen after SON section. In fact, it has been reported that catecholamines exert a proapoptotic effect on lymphocytes in vivo (Stevenson et al. 2001) as well as on MФ culture (Brown et al. 2003, Forneris et al. 2003).

It has been shown that neuropeptides such as NGF and kiss act as regulators of reproductive functions and can influence both the neuronal cell function (at the level of the central nervous system and peripheral system) and the inflammatory response (Sato et al. 2017, Minnone et al. 2017). Most inflammatory cells produce NGF and express TrkA. Thus, NGF induces the production of TNF $\alpha$ and IL-1 $\beta$ in macrophages under activation of TrkA (Minnone et al. 2017). Conversely, pro-inflammatory cytokines promote NGF synthesis in inflammatory tissues (Frossard et al. 2004). In this study, Ngf mRNA expression was higher in PCO M $\Phi$ in relation to Control M $\Phi$, suggesting a role of the neurotropin in inflammatory processes. Studies have been reported on the pro-inflammatory properties of NGF/TrkA in murine M $\Phi$ as well as on the mechanism by which this complex stimulates in vitro TNF $\alpha$ and NO production, through activation of MAPK (Barouch et al. 2001). It is shown here that the SON section has 
an impact on PCO M $\Phi$ by decreasing the $N g f$ mRNA expression, which could contribute to reducing TNF $\alpha$ and NO synthesis in PCO MФ.

On the other hand, Ricu et al. (2012) have suggested that the celiac ganglion is a site of synthesis of kiss, which is transported to the ovary through the SON, acting as a neurotransmitter in this organ. A similar pattern of mRNA expression of Kiss and $\mathrm{Ngf}$ was observed here. We have here found an increase of Kiss expression in PCO $\mathrm{M} \Phi$, which decreases after the SON section. These data may provide evidence that kiss in the spleen could affect macrophage activity. Although the immunomodulatory effects of kiss have not been fully explored yet, it has been reported that the levels of this peptide in plasma rise abruptly during normal pregnancy and have direct effects on the regulatory subpopulations of $\mathrm{T}$ lymphocytes (Gorbunova \& Shirshev 2016). On the other hand, it has been demonstrated that Kiss mRNA expression is increased by TNF $\alpha$, IL-6, MCP-1 and VCAM- 1 in human endothelial cells, and thus, accelerates atherogenesis by enhancing the inflammatory responses (Sato et al. 2017). PCOS is associated with chronic low-grade inflammation and predisposition to hemostatic and atherosclerotic complications (Carvalho et al. 2017), accompanied by high plasma levels of kiss (Chen et al. 2010). In contrast, the decreased expression of kiss mediates acute immune/ inflammatory stress-induced suppression of gonadotropin secretion in female rats (Iwasa et al. 2008).

It is known that PCOS is associated with hyperandrogenemia (Sung et al. 2014). In EV-treated animals, we observed that the serum A2 levels increased in PCO rats while the SON section decreased them. It is possible that the reduced number of TUNEL-positive nuclei in PCO-SON M $\Phi$ may be associated with decreased circulating A2 and hence with pro-apoptotic effect of androgens (Zhao et al. 2013).
Knowing that the SON is the main sympathetic pathway regulating steroidogenesis and follicular growth (Aguado 2002), we evaluated whether the SON section affects the steroidogenic capacity of macrophages in the ovary. The PCO-SON and PCO ovaries responded differently to stimulation with PCO-SON and PCO $\mathrm{M} \Phi$ secretions. The PCO-SON ovaries stimulated with PCO-SON M $\Phi$ secretions released less A2 and P4 compared to PCO ovary. It must be highlighted that PCO-SON M $\Phi$ secretions elicited lower A2 release and higher P4 release from PCO ovaries in relation to PCO M $\Phi$ secretions, suggesting that the SON section modifies the steroidogenic ability of PCO M $\Phi$ secretions. Considering that TNF $\alpha$ production by PCO M $\Phi$ modifies ovarian response by increasing A2 levels (Figueroa et al. 2012), the steroidogenic effect of PCO-SON M $\Phi$ secretions could be associated to a lower release of TNF $\alpha$ by PCO-SON M $\Phi$. In fact, it has been demonstrated that TNF $\alpha$ inhibits gonadotropin supported $\mathrm{P} 4$ production by murine, porcine and bovine ovarian cells (Korzekwa et al. 2008).

Women with PCOS have low levels of P4 related to oligo/anovulation-induced corpus luteum dysfunction as well as high spontaneous abortion rates. However, the mechanism underlying the reduced serum P4 in PCOS are not completely understood (Huang et al. 2016). The evidence obtained here shows that PCO-SON M $\Phi$ secretions improve the release of P4 from PCO ovaries, favoring in part the restitution of the luteal phase. Thus, we have shown that the SON section not only affects the $\mathrm{M} \Phi$ activity but also modifies the ovarian response, observing a differential response to $\mathrm{M} \Phi$ secretion of $\mathrm{P} 4$ release.

The results of our study provide further evidence of the importance of SON in the pathogenesis of the mechanisms underlying the PCOS. The SON bilateral section has the potential to improve the PCO condition in the studied

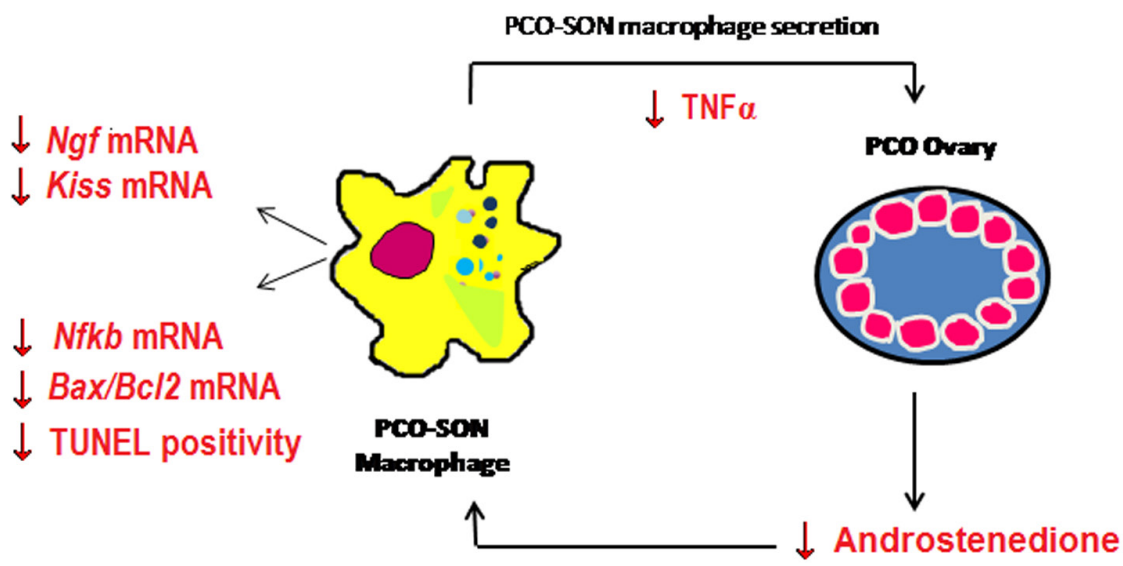

Figure 7

Schematic representation of the effects of superior ovarian nerve (SON) bilateral section on macrophages activity in rats with polycystic ovary (PCO). ( $\downarrow$ : lower concentration than in the PCO group). A full colour version of this figure is available at https://doi.org/10.1530/JOE-17-0736. 
EV-treated animals, not only by the denervation effects directly on the ovary, as also observed by MoralesLedesma et al. (2010), but also by the effects caused by denervation on the steroidogenic ability of spleen $M \Phi$. The influence of the SON on M $\Phi$ activity is demonstrated here, since its manipulation led to modifications of immunological and neural mediators, which might affect ovarian steroidogenesis (Fig. 7). Additional investigations will be necessary to evaluate if the effects observed in this model are maintained in the long-term. Our results support the existence of a functional interaction between the immune, nervous and endocrine systems at peripheral level in PCOS.

\section{Conclusions}

The present study shows that ovarian denervation in PCO rats induced by SON section has an impact on PCO MФ by decreasing the expressions of sympathetic activity markers as $\mathrm{Ngf}$ and Kiss, the release of pro-inflammatory molecules as TNF $\alpha$ and NO and apoptosis. In addition, the steroidogenic ability of $\mathrm{M} \Phi$ secretions is demonstrated by the decrease of A2 release from PCO ovaries under stimulation with PCO-SON M $\Phi$ secretions. This suggests that the SON section, through its effect on $M \Phi$, could improve the altered endocrine environment of PCO. In this work, we have demonstrated that the SON section could contribute to destabilizing the vicious cycle that maintains the hyperandrogenic state. It is possible to suggest that the SON regulates in vivo the macrophage activities of PCO rats. A better understanding of the neuroimmunoendocrine connection involving the $\mathrm{SON}$, spleen $\mathrm{M} \Phi$ and ovary in PCOS will permit to explore the controversial etiology of this disease and propose treatment options consistent with a biomedical approach.

\section{Declaration of interest}

The authors declare that there is no conflict of interest that could be perceived as prejudicing the impartiality of the research reported.

\section{Funding}

This work was supported by Project grant No. 9302, from San Luis University.

\section{Acknowledgements}

The authors appreciate language revision by staff from the Language Institute of Universidad Nacional de San Luis.

\section{References}

Aguado L 2002 Role of the central and peripheral nervous system in the ovarian function. Microscopy Research and Technique 59 462-473. (https://doi.org/10.1002/jemt.10232)

Barouch R, Kazimirsky G, Appel E \& Brodie C 2001 Nerve growth factor regulates TNF-alpha production in mouse macrophages via MAP kinase activation. Journal of Leukocyte Biology 69 1019-1026. (https:// doi.org/10.1189/jlb.69.6.1019)

Barria A, Leyton V, Ojeda SR \& Lara HE 1993 Ovarian steroidal response to gonadotropins and beta-adrenergic stimulation is enhanced in polycystic ovary syndrome: role of sympathetic innervations. Endocrinology 133 2696-2703. (https://doi.org/10.1210/ endo.133.6.8243293)

Bellinger DL, Felten SY, Lorton D \& Felten DL 1989 Origin of noradrenergic innervations of the spleen in rats. Brain, Behavior, and Immunity 3 291-311. (https://doi.org/10.1016/0889-1591(89)90029-9)

Brawer JR, Muñoz J \& Farookhi R 1986 Development of the polycystic ovarian condition (PCO) in the estradiol valerate-treated rat. Biology of Reproduction 35 647-655. (https://doi.org/10.1095/ biolreprod35.3.647)

Brown SW, Meyers RT, Brennan KM, Rumble JM, Narasimhachari N, Perozzi EF, Ryan JJ, Stewart JK \& Fischer-Stenger K 2003 Catecholamines in a macrophage cell line. Journal of Neuroimmunology 135 47-55. (https://doi.org/10.1016/S0165-5728(02)00435-6)

Bryan NS \& Grisham MB 2007 Methods to detect nitric oxide and its metabolites in biological samples. Free Radical Biology and Medicine $\mathbf{4 3}$ 645-657. (https://doi.org/10.1016/j.freeradbiomed.2007.04.026)

Burden HW 1985 The adrenergic innervation of mammalian ovaries In Catecholamines as Hormone Regulators, pp 261-278. Eds N BenJonathan, JM Bahr \& RI Weiner. New York: Raven Press.

Carvalho LM, Ferreira CN, Sóter MO, Sales MF, Rodrigues KF, Martins SR, Candido AL, Reis FM, Silva IF, Campos FM, et al. 2017 Microparticles: inflammatory and haemostatic biomarkers in polycystic ovary syndrome. Molecular and Cellular Endocrinology 443 155-162. (https:// doi.org/10.1016/j.mce.2017.01.017)

Chen X, Mo Y, Li L, Chen Y, Li Y \& Yang D 2010 Increased plasma metastin levels in adolescent women with polycystic ovary syndrome. European Journal of Obstetrics and Gynecology and Reproductive Biology 149 72-76. (https://doi.org/10.1016/j.ejogrb.2009.11.018)

Clarke SA \& Dhillo WS 2016 Kisspeptin across the human lifespan: evidence from animal studies and beyond. Journal of Endocrinology 229 83-98. (https://doi.org/10.1530/JOE-15-0538)

Dissen GA \& Ojeda SR 1999 Ovarian innervation. In Encyclopedia of Reproduction, pp 583-589. Eds E Knobil \& JD Neill. New York, NY, USA: Academic Press.

Farmer P \& Pugin J 2000 -Adrenergic agonists exert their 'antiinflammatory' effects in monocytic cells through the IкB/ NF-кB pathway. American Journal of Physiology: Lung Cellular and Molecular Physiology 279 675-682. (https://doi.org/10.1152/ ajplung.2000.279.4.L675)

Fernandois D, Cruz G, Na EK, Lara HE \& Paredes AH 2017 Kisspeptin level in the aging ovary is regulated by the sympathetic nervous system. Journal of Endocrinology 232 97-105. (https://doi.org/10.1530/ JOE-16-0181)

Figueroa F, Davicino R, Micalizzi B, Oliveros L \& Forneris M 2012 Macrophage secretions modulate the steroidogenesis of polycystic ovary in rats: Effect of testosterone on macrophage pro-inflammatory cytokines. Life Sciences 90 733-739. (https://doi.org/10.1016/j. lfs.2012.03.019)

Figueroa F, Motta A, Acosta M, Mohamed F, Oliveros L \& Forneris M 2015 Role of macrophage secretions on rat polycystic ovary: its effect on apoptosis. Reproduction 150 437-448. (https://doi.org/10.1530/REP15-0216)

Forneris ML \& Aguado L 2002 Neonatal superior ovarian nerve transection disturbs the cycle activity of the female rats. Journal of 
Steroid Biochemistry and Molecular Biology 82 75-82. (https://doi. org/10.1016/S0960-0760(02)00149-8)

Forneris M, Oliveros L \& Aguado L 1999 Effect of secretion of splenocytes after superior ovarian nerve section on the ovarian steroidogenesis. Neuroimmunomodulation 6 1293-1299. (https://doi. org/10.1159/000026387)

Forneris M, Aguado L \& Oliveros L 2003 A neuroimmune regulation at peripheral level on the steroidogenesis of polycystic ovary in rats. Cellular and Molecular Biology 49 965-971.

Forneris M, Rosales E, Ciuffo G \& Oliveros L 2008 Testosterone environment of splenocytes modifies the steroidogenesis of polycystic ovary in rats. Hormone and Metabolic Research 40 239-244. (https:// doi.org/10.1055/s-2007-1022545)

Frossard N, Freund V \& Advenier C 2004 Nerve growth factor and its receptor in asthma and inflammation. European Journal of Pharmacology $\mathbf{5 0 0}$ 453-465. (https://doi.org/10.1016/j. ejphar.2004.07.044)

Gaytán F, Gaytán M, Castellano JM, Romero M, Roa J, Aparicio B, Garrido N, Sánchez-Criado JE, Millar RP, Pellicer A, et al. 2009 KiSS-1 in the mammalian ovary: distribution of kisspeptin in human and marmoset and alterations in KiSS-1 mRNA levels in a rat model of ovulatory dysfunction. American Journal of Physiology: Endocrinology and Metabolism 296 520-531. (https://doi.org/10.1152/ ajpendo.90895.2008)

Gorbunova OL \& Shirshev SV 2016 Molecular mechanisms of the regulation by kisspeptin of the formation and functional activity of Treg and Th17. Biochemistry (Moscow) Supplement Series A: Membrane and Cell Biology 10 180-187. (https://doi.org/10.1134/ S1990747816020069)

Huang S, Pang Y, Yan J, Lin S, Zhao Y, Lei L, Yan L, Li R, Ma C \& Qiao J 2016 Fractalkine restores the decreased expression of StAR and progesterone in granulosa cells from patients with polycystic ovary syndrome. Scientific Reports 6 26205. (https://doi.org/10.1038/ srep26205)

Iwasa T, Matsuzaki T, Murakami M, Shimizu F, Kuwahara A, Yasui T \& Irahara M 2008 Decreased expression of kisspeptin mediates acute immune/inflammatory stress-induced suppression of gonadotropin secretion in female rat. Journal of Endocrinological Investigation $\mathbf{3 1}$ 656-659. (https://doi.org/10.1007/BF03345620)

Kabe Y, Ando K, Hirao S, Yoshida M \& Handa H 2005 Redox regulation of NF-kappaB activation: distinct redox regulation between the cytoplasm and the nucleus. Antioxidants and Redox Signaling 7 395-403. (https://doi.org/10.1089/ars.2005.7.395)

Klein CM \& Burden HW 1988 Anatomical localization of afferent and postganglionic sympathetic neurons innervating the rat ovary. Neuroscience Letters 85 217-222. (https://doi.org/10.1016/03043940(88)90354-0)

Korzekwa A, Murakami S, Wocławek-Potocka I, Bah MM, Okuda K \& Skarzynski DJ 2008 The influence of tumor necrosis factor alpha (TNF) on the secretory function of bovine corpus luteum: TNF and its receptors expression during the estrous cycle. Biology of Reproduction $\mathbf{8}$ 245-262. (https://doi.org/10.1016/S1642-431X(12)60015-1)

Lara HE, Dissen GA, Leyton V, Paredes A, Fuenzalida H, Fiedler JL \& Ojeda SR 2000 An increased intraovarian synthesis of nerve growth factor and its low affinity receptor is a principal component of steroid-induced polycystic ovary in the rat. Endocrinology 141 1059-1072. (https://doi.org/10.1210/endo.141.3.7395)

Liu H, Ma Y, Pagliari LJ, Perlman H, Yu C, Lin A \& Pope RM 2004 TNF-alpha-induced apoptosis of macrophages following inhibition of NF-kappa B: a central role for disruption of mitochondria. Journal of Immunology 172 1907-1915. (https://doi.org/10.4049/ jimmunol.172.3.1907)

Lizneva D, Suturina L, Walker W, Brakta S, Gavrilova-Jordan L \& Azziz R 2016 Criteria, prevalence, and phenotypes of polycystic ovary syndrome. Fertility and Sterility 106 6-15. (https://doi.org/10.1016/j. fertnstert.2016.05.003)
Mignini F, Streccioni V \& Amenta F 2003 Autonomic innervation of immune organs and neuroimmune modulation. Autonomic and Autacoid Pharmacology 23 1-25. (https://doi.org/10.104 6/j.1474-8673.2003.00280)

Minnone G, De Benedetti F \& Bracci-Laudiero L 2017 NGF and its receptors in the regulation of inflammatory response. International Journal of Molecular Sciences 18 e1028. (https://doi.org/10.3390/ ijms18051028)

Morales-Ledesma L, Linares R, Rosas G, Morán C, Chavira R, Cárdenas M \& Domínguez R 2010 Unilateral sectioning of the superior ovarian nerve of rats with polycystic ovarian syndrome restores ovulation in the innervated ovary. Reproductive Biology and Endocrinology 8 99-105. (https://doi.org/10.1186/1477-7827-8-99)

Oakley OR, Frazer ML \& Ko C 2011 Pituitary-ovary-spleen axis in ovulation. Trends in Endocrinology and Metabolism 22 345-352. (https://doi.org/10.1016/j.tem.2011.04.005)

Oliveros L, Forneris M \& Aguado LI 2001 Secretion from neuropeptide treated splenocytes modifies ovarian steroidogenesis. Medicina $\mathbf{6 1}$ 35-40.

Perkins ND 2007 Integrating cell-signalling pathways with NF-kappa B and IKK function. Nature Reviews Molecular Cell Biology 8 49-62. (https://doi.org/10.1038/nrm2083)

Procaccini C, Pucino V, De Rosa V, Marone G \& Matarese G 2014 Neuro-endocrine networks controlling immune system in health and disease. Frontiers in Immunology 5 143. (https://doi.org/10.3389/ fimmu.2014.00143)

Puszynski K, Bertolusso R \& Lipniacki T 2009 Crosstalk between p53 and nuclear factor-kB systems: pro- and anti-apoptotic functions of NF-kB. IET Systems Biology 3 356-367. (https://doi.org/10.1049/ietsyb.2008.0172)

Ricu MA, Ramirez VD, Paredes AH \& Lara HE 2012 Evidence for a celiac ganglion-ovarian kisspeptin neural network in the rat: intraovarian anti-kisspeptin delays vaginal opening and alters estrous cyclicity. Endocrinology 153 4966-4977. (https://doi.org/10.1210/en.2012-1279)

Sagoo P, Chan G, Larkin DF \& George AJ 2004 Inflammatory cytokines induce apoptosis of corneal endothelium through nitric oxide. Investigative Ophthalmology and Visual Science 45 3964-3973. (https:// doi.org/10.1167/iovs.04-0439)

Saller S, Kunz L, Berg D, Berg U, Lara H, Urra J, Hecht S, Pavlik R, Thaler CJ \& Mayerhofer A 2014 Dopamine in human follicular fluid is associated with cellular uptake and metabolism-dependent generation of reactive oxygen species in granulosa cells: implications for physiology and pathology. Human Reproduction 29 555-567. (https:// doi.org/10.1093/humrep/det422)

Sato K, Shirai R, Hontani M, Shinooka R, Hasegawa A, Kichise T, Yamashita T, Yoshizawa H, Watanabe R, Matsuyama TA, et al. 2017 Potent vasoconstrictor kisspeptin-10 induces atherosclerotic plaque progression and instability: reversal by its receptor GPR54 antagonist. Journal of the American Heart Association 6 e005790. (https://doi. org/10.1161/JAHA.117.005790)

Shorakae S, Teede H, de Courten B, Lambert G, Boyle J \& Moran LJ 2015 The emerging role of chronic low-grade inflammation in the pathophysiology of polycystic ovary syndrome. Seminars in Reproductive Medicine 33 257-269. (https://doi. org/10.1055/s-0035-1556568)

Song W, Lu X \& Feng Q 2000 Tumor necrosis factor-alpha induces apoptosis via inducible nitric oxide synthase in neonatal mouse cardiomyocytes. Cardiovascular Research 45 595-602. (https://doi. org/10.1016/S0008-6363(99)00395-8)

Stener-Victorin E, Ploj K, Larsson MB \& Holmäng A 2005 Rats with steroid-induced polycystic ovary develops hypertension and increased sympathetic nervous system activity. Reproductive Biology and Endocrinology 3 44. (https://doi.org/10.1186/1477-7827-3-44)

Stevenson JR, Westermann J, Liebmann PM, Hörtner M, Rinner I, Felsner P, Wölfler A \& Schauenstein K 2001 Prolonged alphaadrenergic stimulation causes changes in leukocyte distribution and 
lymphocyte apoptosis in the rat. Journal of Neuroimmunology $\mathbf{1 2 0}$ 50-57. (https://doi.org/10.1016/S0165-5728(01)00417-9)

Straub RH 2004 Complexity of the bi-directional neuroimmune junction in the spleen. Trends in Pharmacological Sciences 25 640-646. (https:// doi.org/10.1016/j.tips.2004.10.007)

Sung YA, Oh JY, Chung H \& Lee H 2014 Hyperandrogenemia is implicated in both the metabolic and reproductive morbidities of polycystic ovary syndrome. Fertility and Sterility $101840-845$. (https://doi.org/10.1016/j.fertnstert.2013.11.027)

Tan KS, Nackley AG, Satterfield K, Maixner W, Diatchenko L \& Flood PM 2007 Beta2 adrenergic receptor activation stimulates proinflammatory cytokine production in macrophages via PKA- and NF-kappa B-independent mechanisms. Cellular Signalling 19 251-260. (https://doi.org/10.1016/j.cellsig.2006.06.007)

Thorpe LW, Stach RW, Hashim GA, Marchetti D \& Perez-Polo JR 1987 Receptors for nerve growth factor on rat spleen mononuclear cells. Journal of Neuroscience Research 17 128-134. (https://doi.org/10.1002/ jnr.490170206)

ThyagaRajan S \& Priyank HP 2012 Bidirectional communication between the neuroendocrine system and the immune system: relevance to health and diseases. Annals of Neurosciences 19 40-47. (https://doi. org/10.5214/ans.0972.7531.180410)
Wahab F, Atika B, Shahab M \& Behr R 2016 Kisspeptin signalling in the physiology and pathophysiology of the urogenital system. Nature Reviews Urology 13 21-32. (https://doi.org/10.1038/ nrurol.2015.277)

Wojtkiewicz J, Jana B, Kozłowska A, Crayton R, Majewski M, Zalecki M, Baranowski W \& Radziszewski P 2014 Innervation pattern of polycystic ovaries in the women. Journal of Chemical Neuroanatomy 61 147-152. (https://doi.org/10.1016/j. jchemneu.2014.05.003)

Wu R, Van der Hoek KH, Ryan NK, Norman RJ \& Robker RL 2004 Macrophage contributions to ovarian functions. Human Reproduction Update 10 119-133. (https://doi.org/10.1093/humupd/dmh011)

Xiong YL, Liang XY, Yang X, Li Y \& Wei LN 2011 Low-grade chronic inflammation in the peripheral blood and ovaries of women with polycystic ovarian syndrome. European Journal of Obstetrics and Gynecology and Reproductive Biology 159 148-150. (https://doi. org/10.1016/j.ejogrb.2011.07.012)

Zhao KK, Cui YG, Jiang YQ, Wang J, Li M, Zhang Y, Ma X, Diao FY \& Liu JY 2013 Effect of HSP10 on apoptosis induced by testosterone in cultured mouse ovarian granulose cells. European Journal of Obstetrics and Gynecology and Reproductive Biology 171 301-306. (https://doi. org/10.1016/j.ejogrb.2013.09.026)

Received in final form 24 April 2018

Accepted 2 May 2018

Accepted Preprint published online 2 May 2018 